AUTOR:

Keylla Márcia Menezes de Souza

ORIENTADOR:

Prof. Dr. Paulo César de Almeida

Mortalidade perinatal em filhos de mães adolescentes no município de Fortaleza, Ceará

\author{
perinatal mortality in children of adolescent mothers in municipal of Fortaleza, \\ Ceará, Brazil
}

Resumo de tese

Palavras-chave

Mortalidade perinatal Gravidez na adolescência

Saúde Pública

Keywords

Perinatal mortality Pregnancy in adolescence

Public Health

Dissertação de Mestrado em Saúde Pública apresentada ao Programa de Pós-graduação Stricto Sensu em Ciências da Saúde da Universidade Estadual do Ceará, em 27 de dezembro de 2007.

OBJETIVO: avaliar a mortalidade perinatal em filhos de mães adolescentes no município de Fortaleza no ano de 2005. MÉTODOS: trata-se de um estudo de caso-controle realizado em 15 hospitais, públicos e/ou particulares, com (175) casos de morte perinatal e controles os filhos das adolescentes (7.497) que sobreviveram. $\bigcirc$ período do estudo foi de fevereiro a dezembro de 2007; utilizou-se uma fonte secundária. Para analisar a associação entre a mortalidade perinatal e os possíveis fatores de risco foram aplicados os testes $\chi^{2}$ e as odds ratio (OR), fez-se a análise multivariada por meio da regressão logística. RESULTADOS: revelaram que o número de partos em adolescentes permaneceu elevado (23\%), houve discreto predomínio dos óbitos fetais $(54,2 \%)$, ocorridos em sua maior parte em maternidades públicas $(85,4 \%)$. Foi observada uma razão de chances de 42 para prematuridade, 41 para baixo peso ao nascer e 15 para consulta de pré-natal inadequada, que revelaram maior força de associação com a morte perinatal ( $p=0,0001)$. Depois de colocadas no modelo multivariado de regressão logística, permaneceram como fatores de risco. CONCLUSÕES: este estudo aponta a necessidade de adoção de medidas básicas e efetivas de qualificação da assistência à gestante e ao recém-nascido, com o fortalecimento da atenção básica e melhor estruturação dos hospitais, de modo a propiciar a redução da morte perinatal.

AUTORA:

RENATA ZORLINI

ORIENTADOR:

Profa. Dra. Maria Salete Costa Gurgel

\title{
Perfil nutricional pré-operatório de mulheres com câncer ginecológico e de mama
}

Nutritional status of patients with gynecologic and breast cancer

Palavras-chave

Perfil nutrional Avaliação nutricional

Desnutrição

Obesidade

Câncer ginecológico

Câncer de mama

Pré-operatório

Keywords

Nutritional profile Gynecologic cancer

Breast cancer Preoperative Malnutrition
Dissertação de Mestrado apresentada ao Departamento de Tocoginecologia da Faculdade de Ciências Médicas da Universidade Estadual de Campinas (UNICAMP) em 7 de dezembro de 2007.

INTRODUÇÃO: as mulheres com câncer ginecológico ou de mama apresentam, freqüentemente, alterações do estado nutricional, como a desnutrição e a obesidade, devido à própria doença e também ao tratamento a que são submetidas: cirurgia, quimioterapia e/ou radioterapia. Tais alterações podem trazer complicações no pós-operatório, como aumento do período de hospitalização, dos custos hospitalares e piora do prognóstico. Para identificar este problema, a avaliação nutricional pode ser o melhor método para tratar os distúrbios nutricionais, como a desnutrição e/ou a obesidade, melhorar a resposta terapêutica e o prognóstico das pacientes. OBJETIVO: identificar o perfil nutricional pré-operatório de mulheres com câncer ginecológico ou mamário e correlacioná-lo à localização e estágio da doença e tratamentos oncológicos (quimioterapia e/ou radioterapia) prévios. MÉTODOS: trata-se de um estudo de corte transversal, com 250 mulheres avaliadas no pré-operatório de cirurgias oncológicas no CAISM/UNICAMP, pelo índice de massa corpórea (IMC) e pela Avaliação Nutricional Subjetiva Global, no período de agosto de 2003 a abril de 2005. Para análise dos resultados, foram aplicados os testes do $\chi^{2}$ e índice de concordância entre os dois métodos, assumindo-se o nível de significância de 5\%. RESULTADOS: o câncer de mama foi o mais freqüente, predominando em $56,2 \%$. A mediana da idade foi de 52 anos; em cerca de 57\% dos casos, a neoplasia se restringia aos estádios clínicos 0, I e II, e $77 \%$ das mulheres não receberam outro tratamento oncológico pré-cirugico. A Avaliação Nutricional Subjetiva Global detectou $76 \%$ de mulheres eutróficas e $24 \%$ desnutridas, enquanto o IMC identificou 34\% de mulheres eutróficas, $3,6 \%$ desnutridas e $62,4 \%$ com sobrepeso/obesidade. A concordância do diagnóstico de eutrofia e desnutrição pelos dois métodos foi baixa [63,8\%; kappa (IC 95\%)=0,0884 (- 0,07-0,24)]. Não foram observadas correlações entre as avaliações nutricionais e os tratamentos prévios e etádios da doença. Quanto a localização anatômica, segundo a Avaliação Nutricional Subjetiva Global, as mulheres com câncer do corpo do útero eram mais desnutridas que as demais ( $p=0,02)$. CONCLUSÕES: Os achados sugerem que uma avaliação mais criteriosa deva ser empregada para identificação do estado nutricional pré-operatório em mulheres com câncer ginecológico ou mamário. 